\title{
Poultry welfare monitoring: group-level technologies
}

\author{
Marian Stamp Dawkins and Elizabeth Rowe, University of Oxford, UK \\ 1 Introduction \\ 2 Types of automated assessment \\ 3 Automated measures of welfare as part of precision farming \\ 4 Why isn't automated welfare assessment more widely used? \\ 5 Conclusions \\ 6 Future research \\ 7 References
}

\section{Introduction}

In one sense, the health and welfare of commercial poultry is already highly automated. Modern broiler houses, for example, have sophisticated climate control systems that keep birds within the temperature and humidity guidelines recommended by the breeding companies (Yahav et al., 2005; Jones et al., 2005), delivery of food and water is automated and alarms are fitted to ensure a constant supply and light is regulated for both intensity and photoperiod (Corkery et al., 2013). There are environmental sensors to measure temperature (D'Alfonso et al., 1996; Carvalho et al., 2013; Coelho et al., 2016; Curi et al., 2017), ambient dust (Zhao et al., 2009), relative humidity (Carvalho et al., 2013; Coelho et al., 2016; Curi et al., 2017), vibration (Chen et al., 2010), ammonia concentration (Ji et al., 2016) and carbon dioxide concentration (Carvalho et al., 2013; Ji et al., 2016). In other words, the birds' basic needs for food, water and physical comfort can be catered for automatically (Fournel et al., 2017), thus fulfilling at least some of the requirements for good welfare as set out in the Five Freedoms (Brambell, 1965; Webster, 2001), Welfare Quality ${ }^{\circledR}$ (2009), World Organization for Animal Health General Principles (Fraser et al., 2013) and other welfare systems.

But, in another sense, welfare is very far from being automated for any poultry. Welfare is not just defined by the environment provided for an animal (inputs) but what the welfare outcomes actually are (Main et al., 2014). 
Measuring health outcomes such as hockburn and pododermatitis in broilers at the slaughterhouse (Vanderhasselt et al., 2013) is a step in the right direction, but there are many aspects of welfare that simply cannot be measured on dead birds, such as whether they are able to walk without difficulty (Kestin et al., 1992). Currently, the welfare of living birds is generally assessed by human auditors visiting poultry houses and making observations (Ekstrand et al., 1998; de Jong et al., 2012) but this is very labour intensive and gives only a'snapshot' of the state of the flock on the day of the visit (Wathes et al., 2008; Winckler, 2019). It can also risk spreading disease if the same team visits different sites. What would improve poultry welfare generally would be automated ways of measuring welfare outcomes that can be routinely applied to all flocks. Automated monitoring systems allow for non-intrusive assessment of welfare, where information can be collected without the stress of disturbing or handling animals (Wathes et al., 2008). Continuous automated monitoring can also provide a more complete picture of the overall welfare state of animals, and alerting farmers to problems as they arise in real time allows for fast and targeted interventions which will benefit the current flock, compared to traditional welfare assessments that occur at the end of the production cycle (Winckler, 2019; Buscher, 2019). This would benefit producers, consumers and the birds themselves.

In addition to these advantages, automated measures of welfare are often seen as more as more 'objective' than the 'subjective' assessment of a human (Banhazi et al., 2012). While this is potentially a benefit, it is important not to confuse the objectivity of the measurement with how these measurements are to be interpreted in welfare terms, which often contains a subjective or at least a contestable element of what is desirable. Certainly machines can more accurately and more continuously record what animals do than a person observing with the naked eye and writing down what they see. In the limited sense of being more accurate, then, automated measurements are indeed more objective. But the problem of interpreting the data that has been collected and deciding whether or not that is a good measure of welfare remains and is still a matter of controversy. Machine learning for welfare outcomes still needs to have specified what a 'good' or desirable welfare outcome is (Morota et al., 2018). In exactly the same way that the use of machine learning in human medicine needs to be related to desirable outcomes such as longer life, ability to walk or the satisfaction of patients, so too automated assessment of animal welfare still has to have an end-point - what is seen as good or desirable. Part of the reason that automated measures seem objective is that they force us humans to be clearer than we otherwise might be about what our welfare goals are, because we then have to instruct machines what to look for.

So what exactly do we mean by welfare, and, more importantly, in the context of this chapter, can machines measure it? Although there is no universal agreement about how to define animal welfare (Mason and Mendl, 
1993; Fraser, 2008; Mellor and Beausoleil, 2015), it is possible to discern some common threads amongst the various definitions that are in use. An emphasis on good physical health, for example, is universally accepted as the foundation of good animal welfare. For example, the Five Freedoms (Brambell, 1965; Webster, 2001), a widely used system for assessing welfare around the world, lists freedom from disease and injury as one of the key indicators of welfare. This is emphasized just as strongly in more recent versions such as the Ten General Principles (OIE, 2016; Fraser et al., 2013), the Five Provisions or Domains (Mellor, 2016) and the Four Principles put forward by the European Welfare Quality assessment (Welfare Quality, 2009). Furthermore, many of the other criteria used by these and other welfare schemes are specifically aimed at maintaining good health - such as making sure that animals have adequate food and water and are kept in safe comfortable environments in which they are not injured. Many of the most pressing animal welfare issues such as featherpecking in laying hens (Gunnarsson et al., 1999) are seen as serious precisely because of the injuries that result. Conversely, finding ways of preventing disease and stopping hens from injuring themselves by breaking their bones would be widely agreed as improving their welfare. Death, injury and disease are clear welfare outcomes with results that can be measured objectively and are therefore particularly suited to automation.

Of course, there is more to good welfare than simply the absence of disease and injury, as emphasized even more strongly in ideas such as Quality of Life (Bono and Mori, 2005; Broom, 2007) and lives worth living (Wathes, 2010; Mellor, 2016), but, as with humans, these more complex ideas are difficult to define and even more difficult to capture in algorithms (Scott et al., 2007; Taylor and Mills, 2007). This chapter will therefore be mainly based on measures that are the easiest to automate, such as lameness; mortality; disease; leg, foot and skin damage; and vocalizations. Then, as machine algorithms are improving all the time (Nasirahmadi et al., 2017; Liakos et al., 2018), this chapter will additionally look at the steps that have been taken to automate the measurement of other, more complex measures of welfare such as behaviour. The chapter will use examples largely, although not exclusively, from applications to broiler (meat) chickens because this is where the group-level technology has been most developed.

\section{Types of automated assessment}

\subsection{Introduction: group versus individual}

Unlike larger animals such as dairy cows or sows where each animal can be monitored and treated individually (Caja et al., 2016; Buscher, 2019), commercial poultry are kept in groups of many thousands and treated as a group (Winckler, 2019). Feed, vaccinations, medication, drinker height, 
lighting and other factors are not administered to a single individual but set or adjusted to the needs of the whole flock. Even when a particular bird is observed (e.g. during gait scoring; Kestin et al., 1992), this is only a part of a sample to give an estimate of a whole flock score. Individual chickens can be marked or tagged as part of research projects and yield valuable results about individual behaviour (Campbell et al., 2017; Stadig et al., 2018; and Chapter 6 of this volume). For routine commercial farming, however, tagging all birds in a flock of either broilers or layers would present major logistical problems in applying and retrieving the tags, while computer identification and tracking of thousands of birds would be both computationally difficult and expensive. Even if such logistical problems could be overcome, it would currently be impossible to pick up and medicate a single bird among thousands. The large groups in which commercial broilers are kept have therefore led to group-level measures of welfare and to whole group approaches to automating welfare monitoring (Ben Sassi et al., 2016; Berckmans, 2017; Buscher, 2019). It is these group-level measures that are discussed here. In discussing the sensors used for such welfare monitoring (most commonly visual, sound or thermal imaging), we will ask two questions: what are the sensors detecting and how valid is the interpretation of this data in welfare terms? In general, finding sensors to collect data is the easy part. Turning the vast quantities of data that the sensors collect into output that is meaningful in welfare terms is much more difficult.

\subsection{Visual information from CCTV or video}

There are several different approaches to the processing of information coming from cameras. One is to use digital image processing technology to distinguish individual chickens from their background and then to analyse different postures of the birds to identify sick or healthy individuals (Zhuang et al., 2018); to identify particular behaviours (Leroy et al., 2006) such as wing spreading, scratching and preening (Pereira et al., 2013); to track their location in preference tests (Kashiha et al., 2015); and even to detect abnormalities of body oscillation, step frequency and step length in lame broilers (Aydin, 2017a). An alternative approach is not to recognize individual birds as such but to simply see a flock of birds as something that makes patterns of light against a darker background and then to analyse the patterns as the rate of change of brightness (or 'optical flow') in different parts of a moving visual image (Fleet and Weiss, 2005; Fig. 1). This gives a flock-level, rather than an individual bird, measure but has the great advantage that whole frames containing tens or hundreds of individual birds can be assessed together, and the statistical properties of these flow patterns can be derived automatically and continuously (Sonka et al., 1999) using algorithms that are simple enough to deliver results continuously in real time. Clustering of birds can be used to detect that they 


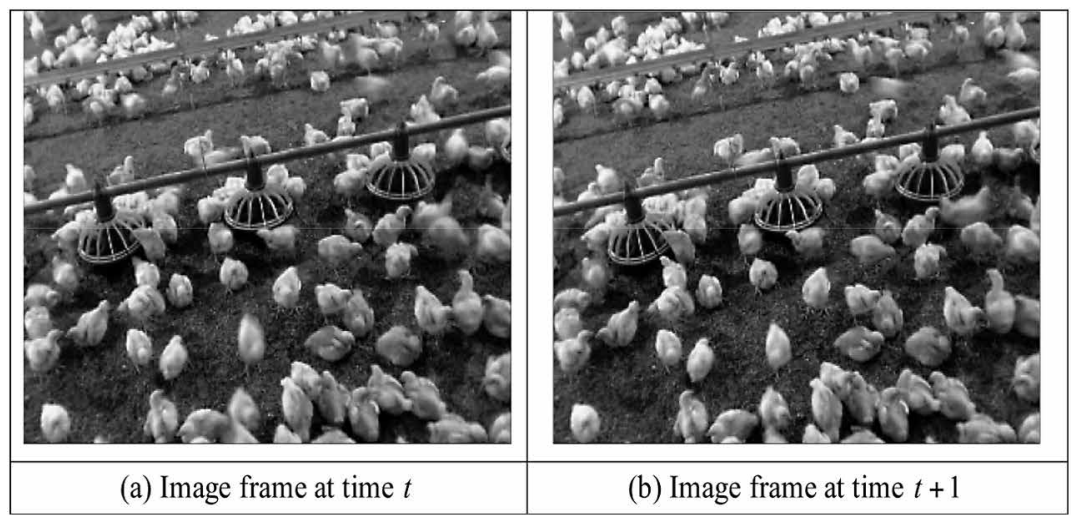

Figure 1 'Optical flow' is the rate of change of image brightness in different parts of a moving visual image, measured by comparing patterns of light and dark in successive video frames over time (Fleet and Weiss, 2005). These changes are combined to give an estimate of local velocity vectors. If all white chickens on the darker background remain stationary from one image to the next, there will no change in the pattern of brightness and no 'flow'. But if some of the chickens move between frames, some white areas will become dark and vice versa, and this is registered as a net 'flow' (Dawkins et al., 2009).

are too cold (Pereira et al., 2012). Yet other approaches involve a combination of individual and group measures so that 'events' such as feather pulling can be recognized but not which individual bird was responsible (Lee et al., 2011).

Using one or more of these techniques, it is now possible to automate the assessment of basic health measures and to validate the results against welfare outcomes assessed in more conventional ways. For example, the eYenamic system takes camera image data every minute, calculates activity and occupation indices for different areas of the screen and is able to link deviations in these indices to welfare assessment of hockburn, pododermaitis and gait score as carried by human observers (Aydin et al., 2015; De Montis et al., 2013; Norton et al., 2016; Aydin, 2017b; Fernandez et al., 2018).

Also using commercial flocks of broiler chickens, Dawkins et al. (2009, 2012) showed that flock movements, as measured by the statistical properties of optical flow patterns, were correlated with key physical health outcomes. Flocks that had lower mean levels of movement and higher kurtosis (a measure of variability) were scored with higher levels of hockburn and foot pad dermatitis at the end of life. Furthermore, these differences were already apparent in young chicks of less than 4 days old (Roberts et al., 2012; Dawkins et al., 2017) before there were any external signs of leg or foot damage. Optical flow patterns were also shown to differ between flocks subsequently testing positive or negative for Campylobacter, one of the major bacterial sources of food poisoning in humans, when chicks were less than a week old (Colles et al., 2016). Campylobacterpositive flocks showed lower mean and higher kurtosis of optical flow than 
flocks that remained free of infection, in line with the previous result that good welfare, including freedom from disease, is associated with more movement (higher mean) and more uniform movement (lower kurtosis). Since infection with Campylobacter is not detectable by normal culture methods until birds are around 21 days old, optical flow patterns were not only correlated with bird health but were also predicting future health status.

A similar ability of optical flow patterns to predict problems before they have detectable clinical effects is suggested by a study by Lee et al. (2011) on feather damage in laying hens. Optical flow patterns of the behaviour of 18-week-old birds were analysed from videos, this time using a hidden Markov model to quantify the number of anomalies or unusual events. The results correlated well with those recorded by a human observer and were predictive of the amount of feather damage when the same flocks were 38 weeks old. Feather damage is often a precursor for outbreaks of feather-pecking (Drake et al., 2010), so these preliminary results suggest that there is a potential for using automated monitoring for giving the warning of flocks at risk of welfare problems.

\subsection{Sound}

The technology to record and analyse sound is well developed, and sound can be used in welfare assessment in a variety of ways. The most obvious is to record sounds made by the birds themselves (Zimmerman et al., 2000). For example, very young chicks are unable to regulate their own body temperature and give high-pitched or distress calls when they are cold (Wood-Gush, 1971). By putting individual chicks into a climate-controlled chamber and altering the temperature, Moura et al. (2008) showed that both the amplitude and the frequency of these calls increased when the temperature dropped. In farm conditions, heat stress leads to distinctive calls by both broilers (Pereira et al., 2014) and layers (Lee et al., 2015). Du et al. (2018) monitored the number of vocalisations/bird both during the day and at night and argued that anomalies in this number of calls given by each bird, particularly at night, could be used for welfare assessment.

Another approach is to use non-communicatory sounds such as the noise made when birds peck food. In one study, a microphone positioned on the side of a feeder was used to estimate when and how much birds were eating (Aydin and Berckmans, 2016).

\subsection{Temperature}

Infra-red thermography is a non-invasive technique for measuring body surface temperature which has been related to stress, emotional arousal and leg pathologies in many bird species, including poultry (McCafferty, 2013). Changes in the surface temperature of the areas of bare skin can be symptomatic of 
short-term stress. For example, Edgar et al. (2013) showed that handling individual hens lead to an initial decrease of as much as $2^{\circ} \mathrm{C}$ in the surface head, eye and comb temperatures followed by an increase. Moe et al. (2017) found that during a 10-minute restraint, footpad temperatures dropped by nearly $0.5^{\circ} \mathrm{C}$, while head region temperatures (e.g. nostrils, comb, wattle, eye) rose by $0.76^{\circ} \mathrm{C}$. Both of these studies suggest that surface temperature changes can be used as measures of welfare but both were carried out in individual birds. Successfully translating these individual measurements into flock-level measures of 'stress' and distinguishing these from changes in the ambient temperature have yet to be achieved. Thermal imaging can also be used to assess feather cover as feathers insulate a bird and prevent heat loss. Cook et al. (2006) showed that the percentage of a thermal image that was within the temperature range of 17-24 $C$ was negatively associated with feather cover, while the percentage within the range of 28-31 C was associated with a lack of feather cover or bare skin. Thermographic images have also been used to register multiple occupancies by laying hens, and the analysis of thermal images is now able count the number of birds in a given nest (Zaninelli et al., 2016, 2017, 2018).

As well as being used to assess the physical state of the birds themselves, thermal imaging cameras can also identify, with high precision, areas in a chicken house with different radiant temperatures and so alert the farmer to particular problems (Coelho et al., 2016).

\subsection{Conclusions}

It is clear that there are now, at least in the development stage, an increasing number of ways in which the welfare of poultry can be monitored automatically. Different sensors give different sorts of information, but for this to be used to maximum effect, it will be necessary to integrate the different sorts of information that are now available and to display them in a form that is accessible to farmers and easy for them to use (Van Hertem et al., 2017; Fournel et al., 2017). The full potential of many of these methods to give an auto mated picture of welfare has yet to be realized.

\section{Automated measures of welfare as part of precision farming}

The automated measures of welfare that are now being developed can potentially provide farmers with valuable information that they can then use to make decisions about how to manage their flocks for better health, for example, whether to put down extra litter or to apply medication. Using such technology, farmers are still in control but are given an extension of their own expertise in the form of extra eyes and ears that operate continuously when they cannot be present. 
More ambitiously, however, the same information can also potentially be used to feed into more integrated automated control systems in which management decisions are taken largely or entirely by a computer. Such precision livestock systems (Werner et al., 2003; Banhazi and Black, 2009; Berckmans, 2017) have been inspired by the now-widespread use of precision agriculture in the growing of crops, where many different variables about both the environment and the growing plants are measured and then actions are automatically taken to match practice to crop needs with the goal of optimizing returns while preserving resources. Here, human decisions often defer to machine algorithms.

However, the idea that the concepts used to grow plants successfully can be transferred directly to poultry farming is controversial. On the one hand, Werkheiser (2018) argues that precision farming allows 'modern, large-scale farms to replicate and even improve on the benefits of caring farmers who know their animals, transferred to a much larger scale. This could be done via closer monitoring than farmers can provide to even a few animals, as well as integration of the data via decision algorithms that improve on the guesswork of traditional stockpersons'. On the other hand, precision farming may make the continued use of intensive systems more likely through making them more efficient and, therefore, more viable, which is of concern to some animal welfare advocates (Stevenson, 2017). For poultry, housed together in large groups and highly sensitive to the details of diet, temperature and air and litter quality, there is a vast potential for not only improving welfare through the use of technology but also reducing welfare through an emphasis on efficiency at the expense of welfare. While improving production and improving welfare are not mutually exclusive (Dawkins, 2016), they do not always coincide. When there is a conflict, what matters is the priority given to welfare.

There are encouraging signs that improving bird welfare is now a priority in much of the research to developing PLF for poultry. In a systematic review Rowe et al. (2019) concluded that $64 \%$ of PLF publications had animal health and welfare as one of their goals, the other being increased production. For the publications that only had one goal, more publications had animal health and welfare as the only goal of the study (40\%) compared to production (27\%). However, with PLF receiving increasing attention around the world and particularly in the USA, China and Belgium, there is an on-going need to ensure that animal welfare is seen as a key priority for sustainability in general and poultry production in particular (Rowe et al., 2019).

\section{Why isn't automated welfare assessment more widely used?}

The development of increasingly sophisticated monitoring systems for poultry farming with their potential to improve both welfare and productivity raises the 
question of why there are not more automated welfare monitoring systems in place on commercial poultry farms. This cannot be explained simply by farmers being unwilling to invest in technology because, as pointed out at the beginning of this chapter, many poultry houses now have complex computercontrolled heating and ventilation systems. Poultry farmers are clearly not averse to technology if it works and gives them something they could not obtain otherwise, It is the next step - the widespread use of automated ways of assessing behaviour and welfare - that is so far not been adopted by poultry producers.

Over 10 years ago, Wathes et al. (2008) suggested that this lack of take-up might be because the equipment was expensive or unreliable or because it was untested under commercial farm conditions, but there has been plenty of time since then for these problems to have been resolved. Yet poultry farming still appears to lag behind other sectors of agriculture in its use of basic health monitoring. In the dairy sector, for example, it is common to use technology to obtain diagnostic data about a range of health- and performance-related criteria (Caja et al., 2016). Poultry farming, with its need to monitor the health and welfare of large numbers of animals, its tight economic margins and the need for transparency in the face of public concern over bird welfare would seem to be even more in need of any help that technology can bring.

A possible answer for the fact that automated welfare is not more widely adopted is that the benefits - economic, production or even welfare - of available automated monitoring systems just simply have not been sufficiently demonstrated for farmers to see the point of investing in them. Caja et al. (2016) pointed out that "dairy farmers will pay for and use technologies that provide what is, to them, a straightforward answer to a straightforward question (should I inseminate cow $x$ ?) when they believe it will have positive economic impact". Although many of the poultry monitoring systems described previously have the potential to improve bird health and welfare, their actual benefits, over and above those that could be obtained by simpler methods, have not yet been demonstrated in practice. For example, keeping growing chicks within the correct temperature and humidity range is critical for their health and welfare (Dawkins et al., 2004), so it may be seen as much simpler to measure this directly with temperature and humidity sensors rather than indirectly by using the spatial distribution of the birds from cameras to determine whether they are too hot or too cold. In other words, good control of the environmental input may be more effective at maintaining the optimal temperature than measuring the results of temperature deviations using a complex and expensive camera or a sound system. If the aim is to monitor how much food chickens are eating, the most obvious way is to measure this directly rather than using the sound the birds make by pecking at food dishes. Water use, another variable that is easily monitored, has been recommended as an easy-to-use measure 
of welfare (RSPCA, 2013; OIE, 2016) since both increases and decreases in water consumption can indicate health problems and the total amount of water consumed by a flock over its lifetime is positively correlated with the prevalence of foot pad dermatitis at slaughter (Manning et al., 2007). Automated assessment of flock behaviour using optical flow also predicts hockburn and pododermatitis and is able to do so more effectively and when the birds are only a few days old (Dawkins et al., 2017) but for farmers to move from the relatively simple method of metering water to automated welfare monitoring with optical flow patterns, they would need to be convinced that the automated system gave them substantially better flock outcomes. Unless and until it can be demonstrated that there are additional benefits from automated welfare assessment, farmers will not invest in or use it. The current situation is that although there is a considerable potential for welfare improvement through automated monitoring, the evidence that welfare is actually improved by using such technology is still missing, even for the most basic health elements of welfare.

When it comes to more complex measures such as activity, or the recognition of specific behaviours such as dustbathing, there is even less evidence of benefit. Unless farmers can be convinced that knowing how much dustbathing or other behaviours their birds are actually doing helps them to keep their flocks healthier, or demonstrably improves the welfare of their birds in some tangible way, it is unlikely that they will invest in the automated ways of measuring it.

\section{Conclusions}

As this chapter shows, technology has a considerable potential for improving welfare through its ability to provide constant monitoring of the health and welfare of poultry throughout their lives and to provide early warning of problems before they become serious. The most promising existing systems are those that measure clearly defined health outcomes in broiler chickens such as lameness and leg and foot defects that are universally agreed to indicate poor welfare and also have economic implications for farmers, but even these have yet to be implemented on a commercial scale. Comparable systems for welfare monitoring in other poultry have yet to be developed.

\section{Future research}

Looking into the future, prime targets for using automated monitoring include occasional events that can have serious welfare consequences such as smothering and feather-pecking in laying hens. 'Smothering' or 'piling' 
(Campbell et al., 2016) is when hens sometimes pile on top of each other to the point that some of them may be killed, while feather-pecking is where hens damage the feathers of other birds, sometimes escalating to the point of injury or even death (Savory, 1995). The causes of these serious welfare issues are incompletely understood (Green et al., 2000; Gebhardt-Henrich and Stratmann, 2016) and although the risk of feather-pecking can be reduced by good management (Nicol et al., 2013), it still occurs, often with devastating effects. If automated monitoring of behaviour could give advance warning of when outbreaks are likely to occur or at least which flocks were most at risk (Lee et al., 2011), this would be a major contribution to improving poultry welfare.

Another use of automated systems could be to monitor the numbers of layers or broilers going outside to fulfil legal or auditing standard requirements for being 'free range' and to monitor a wider range of bird behaviours (Valletta et al., 2017) such as dustbathing and perching to satisfy a public demand for a fully comprehensive picture of bird welfare.

Properly used, automated welfare assessment could combine the wisdom of good stockmanship with far greater attention to individual birds than is currently possible. Smart computing and sensing technology offers the opportunity for shifting poultry production from an entirely group-based approach to a greater consideration of the needs of individual birds. While this shift has been relatively easy for sows and dairy cows where tagging can facilitate individual diets and treatments (Halachmi and Guarino, 2016), future developments may extend this to large groups of untagged poultry. Even crop agriculture does not consider a whole field as a single homogenous unit but treats different parts of the same field differently depending on soil type, moisture levels or the health of the plants growing there. Precision farming for poultry offers the possibility of being similarly 'smart' in not having to treat a flock as a single homogenous whole but rather to be able to apply heat, ventilation or extra litter at least down to a small area of the house.

Whatever the future holds for automated welfare assessment, however, its full potential has yet to be realised in practice. We have argued in this chapter that one of the main reasons for this is that its benefits have not been demonstrated sufficiently to convince poultry farmers to adopt the technology on a large scale. Currently, it is not seen as adding much, if anything, over and above what a stockperson could do on his or her own or with equipment that is already available, such as ventilation control and even water meters. Automated welfare assessment is not yet seen as a worth-while practice, either as a commercial proposition (Jukan et al., 2017), for increasing efficiency or even as a way of achieving its primary purpose of making real improvements to bird welfare. The following are suggested as ways of ensuring that automated 
monitoring fulfils its potential for achieving higher standards of poultry welfare within the context of sustainable food production:

1 The quality of information provided by automated monitoring needs to be improved above its present level so that it is clearly and demonstrably offering farmers something that is better than anything they have available at present. This means that the data obtained from sensors such as cameras and microphones should not be viewed in isolation but rather be part of a fully integrated system that includes all other kinds of information known to impact bird welfare, such as temperature, light and humidity (Van Hertem et al., 2018). To fully achieve this, new and better systems will be needed for analysing and sharing data sets (Jukan et al., 2017) so that best practice can be identified and recommended with the confidence that it is based on the largest possible evidence base. The collection and analysis of such 'Big Data' sets will not only mean better understanding of the factors leading to improved welfare but also the environmental, economic and food safety as well as other advantages of improving welfare (Gocsik et al., 2016; Henningsen et al., 2018). Linking welfare to these other benefits is an important part of making sure animal welfare is given high priority in the decision-making of farmers, governments and the public (Garnett et al., 2013; Dawkins, 2016; Jukan et al., 2017).

2 Automated welfare assessment needs to develop smarter algorithms so that it is both better at detecting welfare problems and able to include more in the definition of 'good welfare' than just the physical health outcomes it currently measures. There is a need for more powerful algorithms that take account of a wider range of welfare measure, but these will need to go hand in hand with more tightly defined and clearly demonstrated definitions of what good welfare is. An algorithm that correctly detects a specific behaviour will not carry much weight as a welfare indicator if that behaviour itself is not linked firmly to what is meant by good welfare, for example by being either an indicator of good health or something that the animals have been shown to want. In other words, the correct interpretation of what automated systems can tell us in welfare terms will be as important to their success as the development of new algorithms themselves.

Another key factor in the welfare value of automation will be the extent to which the technology is able to provide information about which interventions are most appropriate at any given time. Knowledgable systems that can tell farmers when there is a genuine problem with a flock and do so reliably without setting off too many false alarms will help the technology to be widely accepted. But even smarter systems 
that not only detect problems but can also indicate what actions are needed will be an important future development.

3 Public doubts about the welfare implications of automated assessment need to be taken seriously and directly addressed. This is best done by making sure that animal welfare achieves universally high priority with all stakeholders, which in turn means turning the potential welfare advantages of automated assessment into real improvements in the ways listed earlier. As has been emphasized throughout this chapter, automated welfare assessment offers a great promise of improving welfare through constant monitoring, greater care for the individual and early warning of problems and, through the use of large data sets, identifying best practice from around the world. Indeed, as automated measurements become more widespread and provide ever larger data sets, machine learning may provide us with new measures of 'welfare' itself based on a far wider range of measures than is currently possible and using information collected across animals' entire lifetimes.

In addition to improving bird welfare, automated systems have the potential to bring other benefits such as reduced susceptibility to diseases through improved immunity, earlier detection of infection, less waste through reduced mortality, higher standards of food quality and safety and greater job satisfaction for those in charge of poultry (Dawkins, 2016). But the promise has yet to be convincingly fulfilled. Changes in poultry production that make use of automated measurements are likely to continue in the face of rising demand for poultry products, increasing scarcity of human labour to look after birds and increasing public demands for higher welfare standards and transparency by producers.

It is important that the benefits that smart technology appears to offer us are ultimately translated into a reality of better lives for the birds themselves.

\section{References}

Aydin, A. 2017a. Development of an early detection system for lameness of broilers using computer vision. Computers and Electronics in Agriculture 136, 140-6. doi:10.1016/j. compag.2017.02.019.

Aydin, A. 2017b. Using 3D vision camera system to automatically assess the level of inactivity in broiler chickens. Computers and Electronics in Agriculture 135, 4-10. doi:10.1016/j.compag.2017.01.024.

Aydin, A. and Berckmans, D. 2016. Using sound technology to automatically detect the short-term feeding behaviours of broiler chickens. Computers and Electronics in Agriculture 121, 25-31. doi:10.1016/j.compag.2015.11.010.

Aydin, A., Bahr, C. and Berckmans, D. 2015. Automatic classification of measures of lying to assess the lameness of broilers. Animal Welfare 24(3), 335-43. doi:10.7120/09627286.24.3.335. 
Banhazi, T. M. and Black, J. L. 2009. Precision livestock farming: a suite of electronic systems to ensure the application of best practice management on livestock farms. Australian Journal of Multi-Disciplinary Engineering 7(1), 1-14. doi:10.1080/144883 88.2009.11464794.

Banhazi, T. M., Lehr, H., Black, J. L., Crabtree, H., Schofield, P., Tscharke, M. and Berckmans, D. 2012. Precision Livestock Farming: an international review of scientific and commercial aspects. International Journal of Agricultural and Biological Engineering 5, 1-9.

Ben Sassi, N., Averos, X. and Estevez, I. 2016 Technology and poultry welfare. Animals 6(10), 62. doi:10.3390/ani6100062.

Berckmans, D. 2017. General introduction to precision livestock farming. Animal Frontiers 7(1), 6-11. doi:10.2527/af.2017.0102.

Brambell, F. W. R. 1965. Report of the technical committee to enquire into the welfare of animals kept under intensive husbandry systems. Doc. 2836. Her Majesty's Stationery Office, London, UK. Reprinted 1970.

Bono, G. and Mori, B. D. 2005. Animals and their quality of life: considerations beyond mere welfare. Veterinary Research Communications 29(Suppl. 2), 165-8.

Broom, D. M. 2007. Quality of Life means welfare: how is it related to other concepts and assessed? Animal Welfare 16, 43-53.

Buscher, W. 2019. Digitization of the barn. Zuchtungskunde 91, 35-44.

Caja, G., Castro-Costa, A. and Knight, C. H. 2016. Engineering to support wellbeing of dairy animals: background and current scenario. Journal of Dairy Research 83(2), 136-47. doi:10.1017/S0022029916000261.

Campbell, D. L. M., Makagon, M. M., Swanson, J. C. and Siegford, J. M. 2016. Litter use by laying hens in a commercial aviary: dustbathing and piling. Poultry Science 95(1), 164-75. doi:10.3382/ps/pev183.

Campbell, D. L. M., Hinch, G. N., Dyall, T. R., Warin, L., Little, B. A. and Lee, C. 2017. Outdoor stocking density in free-range laying hens: radio-frequency identification of impacts on range use. Animal 11(1), 121-30. doi:10.1017/S1751731116001154.

Carvalho, T. M. R., Massari, J. M., Sabino, L. A. and Moura, D. J. 2013. Sensor placement to reach thermal comfort and air quality in broiler housing. Precision Livestock Farming 2013 - Papers Presented at the 6th European Conference on Precision Livestock Farming, ECPLF 2013, pp. 945-52.

Chen, Y., Ni, J. Q., Diehl, C. A., Heber, A. J., Bogan, B. W. and Chai, L. L. 2010. Large scale application of vibration sensors for fan monitoring at commercial layer hen houses. Sensors (Basel, Switzerland) 10(12), 11590-604. doi:10.3390/s101211590.

Coelho, D. J. de R., Tinôco, I. de F. F., Baptista, F. J., Souza, C. de F., Sousa, F. C. de, Cruz, V. F. da, Vieira, M. de F. A., Mendes, M. A. dos S. A., Oliveira, K. P. de and Barbari, M. 2016. Mapping the thermal comfort index in laying hens facilities. Organising Committee, CIGR 2016, Aarhus, Denmark.

Colles, F. M., Cain, R. J., Nickson, T., Smith, A. L., Roberts, S. J., Maiden, M. C. J., Lunn, D. and Dawkins, M. S. 2016. Monitoring chick flock behaviour provides early warning of infection by human pathogen Campylobacter. Proceedings of the Royal Society of London, Series B 283(1822).

Cook, N. J., Smykot, A. B., Holm, D. E., Fasenko, G. and Church, J. S. 2006. Assessing feather cover of laying hens by infrared thermography. Journal of Applied Poultry Research 15(2), 274-9. doi:10.1093/japr/15.2.274. 
Corkery, G., Ward, S., Kenny, C. and Hemmingway, P. 2013. Incorporating smart sensing technology into the poultry industry. Journal of World's Poultry Research 3, 106-28.

Curi, T. M. RdC., Conti, D., Vercellino, RdA., Massari, J. M., Moura, D. Jd, Souza, Z. Md and Montanari, R. 2017. Positioning of sensors for control of ventilation systems in broiler houses: a case study. Scientia Agricola 74(2), 101-9. doi:10.1590/1678-992x-2015-0369.

D'Alfonso, T. H., Manbeck, H. B. and Roush, W. B. 1996. A case study of temperature uniformity in three laying hen production buildings. Transactions of the American Society of Agricultural Engineers 3, 669.

Dawkins, M. S. 2016. Animal welfare and efficient farming: is conflict inevitable? Animal Production Science 57(2), 201. doi:10.1071/AN15383.

Dawkins, M. S., Donnelly, C. A. and Jones, T. A. 2004. Chicken welfare is influenced more by housing conditions than by stocking density. Nature 427(6972), 342-4. doi:10.1038/nature02226.

Dawkins, M. S., Lee, H.-J.,Waitt, C. D. and Roberts, S. J. 2009. Optical flow patterns in broiler chicken flocks as automated measures of behaviour and gait. Applied Animal Behaviour Science 119(3-4), 203-9. doi:10.1016/j.applanim.2009.04.009.

Dawkins, M. S., Cain, R. and Roberts, S. J. 2012. Optical flow, flock behaviour and chicken welfare. Animal Behaviour 84(1), 219-23. doi:10.1016/j.anbehav.2012.04.036.

Dawkins, M. S., Roberts, S. J., Cain, R. J., Nickson, T. and Donnelly, C. A. 2017. Early warning of footpad dermatitis and hock burn in broiler chicken flocks using optical flow, body weight and water consumption. Veterinary Record 180(20), 499. doi:10.1136/ vr.104066.

de Jong, I. C.,van Harn, J., Gunnink, H., Hindle, V. A. and Lourens, A. 2012. Footpad dermatitis in Dutch broiler flocks: prevalence and factors of influence. Poultry Science 91(7), 1569-74. doi:10.3382/ps.2012-02156.

De Montis, A., Pinna, A., Barra, M. and Vranken, E. 2013. Analysis of poultry eating and drinking behavior by software eYeNamic. Journal of Agricultural Engineering 44(2s), 166-72. doi:10.4081/jae.2013.275.

Drake, K. A.,Donnelly, C. A. and Dawkins, M. S. 2010. Influence of rearing and lay risk factors on propensity for feather damage in laying hens. British Poultry Science 51(6), 725-33. doi:10.1080/00071668.2010.528751.

Du, X., Lao, F. and Teng, G. 2018. A sound source localization analytical method for monitoring the abnormal night vocalisations of poultry. Sensors 18(9), Article No. 2906. doi:10.3390/s18092906.

Edgar, J. L., Nicol, C. J., Pugh, C. A. and Paul, E. S. 2013. Surface temperature changes in response to handling in domestic chickens. Physiology and Behavior 119, 195-200. doi:10.1016/j.physbeh.2013.06.020.

Ekstrand, C., Carpenter, T. E., Andersson, I. and Algers, B. 1998. Prevalence and control of foot-pad dermatitis in broilers in Sweden. British Poultry Science 39(3), 318-24. doi:10.1080/00071669888845.

Fernandez, A. P., Norton, T., Tullo, E., van Hertem, T., Youssef, A., Exadaktylos, V., Vranken, E., Guarino, M. and Berckmans, D. 2018. Real-time monitoring of broiler flock's welfare status using camera-based technology. Biosystems Engineering 173, $103-$ 14. doi:10.1016/j.biosystemseng.2018.05.008.

Fleet, D. J. and Weiss, Y. 2005. Optimal flow estimation. In: Paragios, N., Chen, Y. and Faugeras, O. (Eds), Mathematical Models for Computer Vision. Springer, New York, NY, pp. 239-58. 
Fournel, S., Rousseau, A. N. and Laberge, B. 2017. Rethinking environmental control strategy of confined animal housing systems through precision livestock farming. Biosystems Engineering 155, 96-123. doi:10.1016/j.biosystemseng.2016.12.005.

Fraser, D. 2008. Understanding Animal Welfare: the Science in Its Cultural Context. WileyBlackwell, Oxford, UK.

Fraser, D., Duncan, I. J. H., Edwards, S. A., Grandon, T., Gregory, N. G., Guyonnet, V., Hemsworth, P. H., Huertas, S. M., Huzzey, J. M., Mellor, D. J., Mench, J. A., Spinka, M. and Whay, H. R. 2013. General principles for the welfare of animals in production systems: the underlying science and its application. Veterinary Journal 198(1), 1927. doi:10.1016/j.tvjl.2013.06.028.

Garnett, T., Appleby, M. C., Balmford, A., Bateman, I. J., Benton, T. G., Bloomer, P., Burlingame, B., Dawkins, M., Dolan, L., Fraser, D., Herrero, M., Hoffmann, I., Smith, P., Thornton, P. K., Toulmin, C., Vermeulen, S. J. and Godfray, H. C. 2013. Sustainable intensification in agriculture: premises and policies. Science 341(6141), 33-4. doi:10.1126/science.1234485.

Gebhardt-Henrich, S. G. and Stratmann, A. 2016. What is causing smothering in laying hens? Veterinary Record 179(10), 250-1. doi:10.1136/vr.i4618.

Gocsik, É., Brooshooft, S. D., de Jong, I. C. and Saatkamp, H. W. 2016. Cost-efficiency of animal welfare in broiler production: a pilot study is the Welfare Quality ${ }^{\circledR}$ assessment protocol. Agricultural Systems 146, 55-69. doi:10.1016/j.agsy.2016.04.001.

Green, L. E., Lewis, K., Kimpton, A. and Nicol,C. J. 2000. Cross-sectional study of the prevalence of feather pecking of laying hens in alternative systems and its associations with management and disease. Veterinary Record 147(9), 233-8. doi:10.1136/vr.147.9.233.

Gunnarsson, S., Keeling, L. J. and Svedberg, J. 1999. Effect of rearing factors on the prevalence of floor eggs, cloacal cannibalism and feather pecking in commercial flocks of loose housed laying hens. British Poultry Science 40(1), 12-8. doi:10.1080/00071669987773.

Halachmi, I. and Guarino, M. 2016. Editorial: precision livestock farming: a 'per animal' approach using advanced monitoring technologies. Animal 10(9), 1482-3. doi:10.1017/S1751731116001142.

Henningsen, A., Czekaj, T. G., Forkman, B., Lund, M. and Nielsen, A. S. 2018. The relationship between animal welfare and economic perfomance at farm level: a quantitative study of Danish pig producers. Journal of Agricultural Economics 69(1), 142-62. doi:10.1111/1477-9552.12228.

Ji, B., Zheng, W., Gates, R. S. and Green, A. R. 2016. Design and performance evaluation of the upgraded portable monitoring unit for air quality in animal housing. Computers and Electronics in Agriculture 124, 132-40. doi:10.1016/j.compag.2016.03.030.

Jones, T. A., Donnelly, C. A. and Dawkins, M. S. 2005. Environmental and management factors affecting the welfare of chickens on commercial farms in the United Kingdom and Denmark stocked at five densities. Poultry Science 84(8), 1155-65. doi:10.1093/ ps/84.8.1155.

Jukan, A.,Masip-Bruin, X.and Amla, N. 2017. Smart computing and sensing technologies for animal welfare: a systematic review. ACM Computing Surveys 50(1), 1-27. doi:10.1145/3041960.

Kashiha, M. A., Green, A. R., Sales, T. G., Bahr, C., Berckmans, D. and Gates, R. S. 2015. Application of image processing on hen tracking in an environmental preference 
chamber. Precision Livestock Farming 2015 - Papers Presented at the 7th European Conference on Precision Livestock Farming, ECPLF 2015, pp. 185-94.

Kestin, S. C., Knowles, T. G., Tinch, A. E. and Gregory, N. G. 1992. Prevalence of leg weakness in broiler chickens and the relationship with genotype. Veterinary Record $133,190-4$.

Lee, H. J., Roberts, S. J., Drake, K. A. and Dawkins, M. S. 2011. Prediction of feather damage in laying hens using optical flows and Markov models. Journal of the Royal Society, Interface 8(57), 489-99. doi:10.1098/rsif.2010.0268.

Lee, J., Noh, B., Jang, S., Park, D., Chung, Y. and Chang, H. H. 2015. Stress detection and classification of laying hens by sound analysis. Asian-Australasian Journal of Animal Sciences 28(4), 592-8. doi:10.5713/ajas.14.0654.

Leroy, T., Vranken, E., Van Brecht, A., Struelens, E., Sonck, B. and Berckmans, D. 2006. A computer vision method for on-line behavioral quantification of individually caged poultry. Transactions of the ASABE 49(3), 795-802. doi:10.13031/2013.20462.

Liakos, K. G., Busato, P., Moshou, D., Pearson, S. and Bochtis, D. 2018. Machine learning in agriculture: a review. Sensors 18(8), Article No. 2674. doi:10.3390/s18082674.

Main, D. C. J., Mullan, S., Atkinson, C., Cooper, M., Wrathhall, J. H. M. and Blokhuis, H. J. 2014. Best practice framework for animal welfare certification schemes. Trends in Food Science and Technology 37(2), 127-36. doi:10.1016/j.tifs.2014.03.009.

Manning, L., Chadd, S. A. and Baines, R. N. 2007. Water consumption in broiler chickens: a welfare indicator. World's Poultry Science Journal 63(1), 63-71. doi:10.1017/ S0043933907001274.

Mason, G. and Mendl, M. 1993. Why is there no simple way of measuring animal welfare? Animal Welfare 2, 301-20.

McCafferty, D. J. 2013. Applications of thermal imaging in avian science. Ibis 155(1), 4-15. doi:10.1111/ibi.12010.

Mellor, D. J. 2016. Updating animal welfare thinking: moving beyond the 'Five Freedoms' towards 'a life worth living'. Animals 6(3), 21. doi:10.3390/ani6030021.

Mellor, D. J. and Beausoleil, N. J. 2015. Extending the 'Five Domains' model for animal welfare assessment to incorporate positive welfare states. Animal Welfare 24(3), 241-53. doi:10.7120/09627286.24.3.241.

Moe, R. O., Bohlin, J., Flo, A., Vasdal, G. and Stubsjoen, S. M. 2017. Hot chicks, cold feet. Physiology and Behavior 179, 42-8. doi:10.1016/j.physbeh.2017.05.025.

Morota, G., Ventura, R. V., Silva, F. F., Koyama, M. and Fernando, S. C. 2018. Machine learning and data mining advance predictive big data in precision animal agriculture. Journal of Animal Science 96(4), 1540-50. doi:10.1093/jas/sky014.

Moura, C. J., Naas,I., Alves, E. C. S., Carvalho, T. M. R., Vale, M. M. and Lima, K. A. O. 2008. Scientific Agriculture 119, 178-83.

Nasirahmadi, A., Edwards, S. A. and Sturm, B. 2017. Implementation of machine vision for detecting behaviour of cattle and pigs. Livestock Science 202, 25-38. doi:10.1016/j. livsci.2017.05.014.

Nicol, C. J., Bestman, M., Gilani, A. M., De Haas, E. N., De Jong, I. C., Lambton, S., Wagenaar, J. P., Weeks, C. A. and Rodenburg, T. B. 2013. The prevention and control of feather pecking: applications to commercial systems. World's Poultry Science Journal 69(4), 775-88. doi:10.1017/S0043933913000809.

Norton, T., Vranken, E., Exadaktylos, V., Berckmans, D., Lehr, H., Vessier, I., Blokhuis, H. and Berckmans, D. 2016. Implementation of Precision Livestock Farming (PLF)technology 
on EU farms: results from the EU-PLF project. In: CIGR-AgEng Conference, 26-29 June 2016, Aarhus, Denmark. Abstracts and full papers, 2016, pp. 1-7.

Pereira, D. F., Nääs, I. D. A., Gabriel Filho, L. R. A. and Neto, M. M. 2012. Cluster index for accessing thermal comfort for broiler breeders. ASABE - 9th International Livestock Environment Symposium 2012, ILES 2012, pp. 207-12.

Pereira, D. F., Miyamoto, B. C. B., Maia, G. D. N., Tatiana Sales, G., Magalhães, M. M. and Gates, R. S. 2013. Machine vision to identify broiler breeder behavior. Computers and Electronics in Agriculture 99, 194-9. doi:10.1016/j.compag.2013.09.012.

Pereira, E. M., Naas, IdA. and Garcia, R. G. 2014. Identification of acoustic parameters for broiler welfare estimates. Engenharia Agricola 34(3), 413-21. doi:10.1590/ S0100-69162014000300004.

OIE. 2016. Chapter 7. Animal Welfare and broiler chicken production systems. Terrestrial Animal Health Code. OIE. World Organisation for Animal Health, pp. 1-7. Available at: $\quad$ http://www.oie.int/index.php?id=169\&L=0\&htmfile=chapitre_aw:broiler_ch icken.ht (accessed on 08 July 2016).

Roberts, S. J., Cain, R. and Dawkins, M. S. 2012. Prediction of welfare outcomes for broiler chickens using Bayesian regression on continuous optical flow data. Journal of the Royal Society, Interface 9(77), 3436-43. doi:10.1098/rsif.2012.0594.

Rowe, E., Dawkins, M. S. and Gebhardt-Heinrich, S. 2019. A systematic review of precision livestock farming in the poultry sector: is technology focussed on improving animal welfare? Animals 9(9), Article 614.

RSPCA. 2013. Welfare Standards for Chickens. Royal Society for the Prevention of Cruelty to Animals, Horsham, UK.

Savory, C. J. 1995. Feather peckimg and cannibalism. World's Poultry Science Journal 51(2), 215-19. doi:10.1079/WPS19950016.

Scott, E. M., Nolan, A., Reid, J. and Wiseman-Orr, M. L. 2007. Can we really measure animal QoL? Methodologies for measuring Qol in people and other animals. Animal Welfare 16, 17-24.

Sonka, M., Hlavac, V. and Boyle, R. 1999. Image Processing Analysis and Machine Vision (2nd edn.). PWS Publishing, London, UK.

Stadig, L. M., Ampe, B., Rodenburg, T. B., Reubens, B., Maselyne, J., Zhuang, S., Criel, J. and Tuyttens, F. A. M. 2018. An automated positioning system for monitoring chickens' location: accuracy and registration success in a free-range area. Applied Animal Behaviour Science 201, 31-9. doi:10.1016/j.applanim.2017.12.010.

Stevenson, P. 2017. Precision livestock farming: could it drive the livestock sector in the wrong direction? Available at: https://www.ciwf.org.uk/media/7431928/plf-could-it -drive-the-livestock-sector-in-the-wrong-direction.pdf (accessed on 9 May 2019).

Taylor, K. D. and Mills, D. S. 2007. Is quality of life a useful concept for companion animals? Animal Welfare 16, 55-65.

Valletta, J. J., Torney, C., Kings, M., Throbton, A. and Madden, J. 2017. Applications of Machine learning in animal behaviour studies. Animal Behaviour 124, 203-20. doi:10.1016/j.anbehav.2016.12.005.

Vanderhasselt, R. F., Sprenger, M., Duchateau, L. and Tuyttens, F. A. 2013. Automated assessment of footpad dermatitis in broiler chickens at the slaughterline: evaluation and correspondence with human expert scores. Poultry Science 92(1), 12-8. doi:10.3382/ps.2012-02153.

Van Hertem, T., Rooijahkers, L., Berckmans, D., Peña Fernández, A., Norton, T., Berckmans, D. and Vranken, E. 2017. Appropriate data visualisation is key to Precision Livestock 
Farming acceptance. Computers and Electronics in Agriculture 138, 1-10. doi:10.1016/j.compag.2017.04.003.

Van Hertem, T., Norton, T., Berckmans, D. and Vranken, E. 2018. Predicting broiler gait scores from activity monitoring and flock data. Biosystems Engineering 173, 93-102. doi:10.1016/j.biosystemseng.2018.07.002.

Wathes, C. M. 2010. Lives worth living? Veterinary Record 166(15), 468-9. doi:10.1136/ vr.c849.

Wathes, C. M., Kristensen, H. H., Aerts, J. -M. and Berckmans, D. 2008. Is precision livestock farming an engineer's daydream or nightmare, an animal's friend of foe and a farmer's panacea or pitfall? Computers and Electronics in Agriculture 64(1), 2-10. doi:10.1016/j.compag.2008.05.005.

Webster, A. J. F. 2001. Farm animal welfare: the five freedoms and the free market. Veterinary Journal 161(3), 229-37. doi:10.1053/tvjl.2000.0563.

Welfare Quality. 2009. Assessment Protocol for Poultry, Broiler and Laying Hens. Welfare Quality, Lelystad, The Netherlands. Available at: http://www.animalwelfareplatfo rm.eu/Twelve-farm-animal-welfare-criteria.php.

Werkheiser, I. 2018. Precision livestock farming and farmers' duties to livestock. Journal of Agricultural and Environmental Ethics 31(2), 181-95. doi:10.1007/ s10806-018-9720-0.

Werner, A., Jarfe, A., Stafford, J. V. and Cox, S. W. R. 2003. European Conference on Precision Livestock Farming (1st: 2003 : Berlin G) and European Conference on Precision Agriculture (4th: 2003 : Berlin G) 2003 Programme Book of the Joint Conference of ECPA-ECPLF. Wageningen Academic, Wageningen, the Netherlands.

Winckler, C. 2019. Assessing animal welfare at the farm level: do we care sufficiently about the individual? Animal Welfare 28(1), 77-82. doi:10.7120/09627286.28.1.077.

Wood-Gush, D. G. M. 1971. The Behaviour of the Domestic Fowl. Heinemann, London, UK.

Yahav, S., Shinder, D., Tanny, J. and Cohen, S. 2005. Sensible heat loss: the broiler's paradox. World's Poultry Science Journal 61(3), 419-34. doi:10.1079/WPS200453.

Zaninelli, M., Redaelli,V., Tirloni, E., Bernardi, C., Dell'Orto, V. and Savoini, G. 2016. First results of a detection sensor for the monitoring of laying hens reared in a commercial organic egg production farm based on the use of infrared technology. Sensors (Basel, Switzerland) 16(10). doi:10.3390/s16101757.

Zaninelli, M., Redaelli, V., Luzi, F., Bontempo, V., Dell'Orto, V. and Savoini, G. 2017. A monitoring system for laying hens that uses a detection sensor based on infrared technology and image pattern recognition. Sensors 17(6). doi:10.3390/s17061195.

Zaninelli, M., Redaelli, V., Luzi, F., Mitchell, M., Bontempo, V., Cattaneo, D., Dell'Orto, V. and Savoini, G. 2018. Development of a machine vision method for the monitoring of laying hens and detection of multiple nest occupations. Sensors 18(1). doi:10.3390/ s18010132.

Zhao, Y., Aarnink, A. J. A., Hofschreuder, P. and Groot Koerkamp, P. W. G. 2009. Evaluation of an impaction and a cyclone pre-separator for sampling high PM10 and PM2.5 concentrations in livestock houses. Journal of Aerosol Science 40, 868-78.

Zhuang, X. L., Bi, M. N., Guo, J. L.,Wu, S. Y. and Zhang, T. 2018. Development of an early warning algorithm to detect sick broilers. Computers and Electronics in Agriculture 144, 102-13. doi:10.1016/j.compag.2017.11.032.

Zimmerman, P. H., Koene, P. and Van Hooff, J. A. 2000. The vocal expression of feeding motivation and frustration in domestic laying hens. Applied Animal Behaviour Science 69, 265-73. doi:10.1016/s0168-1591(00)00136-2. 
